\title{
Evaluation of effectiveness and analysis of goal-directed blood transfusion in peri-operation of major orthopedic surgery in elderly patients
}

\author{
HONG ZHENG, JIAN-JIANG WU and JIANG WANG \\ Department of Anesthesiology, The First Affiliated Hospital of Xinjiang Medical University, \\ Urumqi 830054, P.R. China
}

Received September 5, 2012; Accepted November 6, 2012

DOI: $10.3892 /$ etm.2012.834

\begin{abstract}
Through the establishment of blood transfusioneffectiveness assessment criteria, we aimed to evaluate and analyze the effectiveness of peri-operative red blood cell transfusion for major orthopedics in elderly patients. Male and female patients $(n=106)$ with American Society of Anesthesiologists (ASA) stage II-III, aged 60-80 years and scheduled for elective orthopedic surgery were randomly divided into 2 groups: group I ( $\mathrm{n}=52)$, received the traditional method of red blood cell transfusion and group II $(n=54)$ received hemoglobin $(\mathrm{Hb})$ and hematocrit $(\mathrm{Hct})$ goal-directed red blood cell (RBC) transfusion. We compared the changes in $\mathrm{Hb}, \mathrm{Hct}, \mathrm{RBC}$, platelet (PLT), prothrombin time (PT), activated partial thromboplastin time (APTT), alveolar-arterial oxygen partial pressure $\left[\mathrm{P}(\mathrm{A}-\mathrm{a}) \mathrm{O}_{2}\right]$, oxygenation index $(\mathrm{OI})$ and Vigileo monitoring indicators following RBC composition transfusion before and after surgery. We also monitored wound healing time, number of hospitalization days and intensive care unit (ICU) transfer rate. Blood transfusion-effectiveness assessment criteria were used to evaluate the efficacy and safety of $\mathrm{Hb}$ and $\mathrm{Hct}$ goal-directed RBC transfusion in orthopedic elderly patients. The two groups demonstrated an efficiency of 61.5 and $72.2 \%$, respectively $(\mathrm{P}>0.05)$. The $\mathrm{P}(\mathrm{A}-\mathrm{a}) \mathrm{O}_{2}$ and $\mathrm{OI}$ in the two groups were not significantly different $(\mathrm{P}>0.05)$. Compared with the traditional $\mathrm{RBC}$ transfusion group, the $\mathrm{Hb}$ and Hct goal-directed RBC transfusion group presented increased RBC, $\mathrm{Hb}$ and Hct, as well as decreased PT and APTT and shorter wound healing time. The number of days of hospitalization and ICU transfer rate also decreased $(\mathrm{P}<0.05)$. The $\mathrm{Hb}$ and Hct goal-directed method for RBC transfusion
\end{abstract}

Correspondence to: Dr Jiang Wang, Department of Anesthesiology, The First Affiliated Hospital of Xinjiang Medical University, 137 Liyushannan Road, Urumqi 830054, P.R. China E-mail: hongzhengen@126.com

Key words: orthopedic elderly patients, goal orientation, blood transfusion, effectiveness was found to be more effective as a form of peri-operative $\mathrm{RBC}$ transfusion for major orthopedics in elderly patients.

\section{Introduction}

Blood protection in major orthopedic surgery has become a focus of attention and research, particularly with prolonged life expectancy, the development of orthopedic surgery technology and the constantly enhanced blood conservation awareness. In major orthopedic surgery, the proportion of elderly patients increases each year (1). Due to the decline in organ function, elderly patients have a significantly increased postoperative infection rate and mortality compared with young and middle-aged patients under the same condition of blood loss $(2,3)$. Significant blood loss is one cause of peri-operative complications in elderly patients $(4,5)$. A method to evaluate the effectiveness of blood transfusions is a current key issue. However, in all peri-operative blood transfusion guides, only the circumstances in which blood transfusions are needed is mentioned, not how to correctly and reasonably give a blood transfusion to elicit the best effect. Therefore, an evaluation system of blood transfusion effectiveness is needed. In this study, we compared the traditional red blood cell (RBC) transfusion method to the hemoglobin $(\mathrm{Hb})$ and hematocrit $(\mathrm{Hct})$ goal-directed RBC transfusion method to objectively evaluate the effectiveness of blood transfusion in peri-operation of major surgery in elderly patients, thereby providing theoretical basis to establish reasonable and individual clinical blood conservation strategies.

\section{Materials and methods}

Subjects. This study was approved by the Ethics Committee of the First Affiliated Hospital of Xinjiang Medical University and patients provided informed consent. A total of 106 male and female patients were included from orthopedic elective surgeries. Patients were classified as American Society of Anesthesiologists (ASA) stage II-III, according to their systemic conditions. The average age was $70 \pm 6$ years and the average weight was $68 \pm 13 \mathrm{~kg}$. Eight patients had a history of more than two blood transfusions. Patients were randomly divided into the control group $(\mathrm{n}=52)$ and the experimental 
group ( $n=54)$ using the envelope method. The control group (group 1) received the traditional RBC transfusion method and the experimental group (group 2) received the $\mathrm{Hb}$ and $\mathrm{Hct}$ goal-directed RBC transfusion method.

The inclusion criteria were as follows: according to the World Health Organisation (WHO) criteria, patients were aged 60-80 years, with cardiac function $\leq$ level II and did not have a preoperative history of mental or neurological disease or transfusion allergy. The expected intraoperative blood loss was $>20 \%$ of the total blood volume. Patients were required to be in accordance with the transfusion indications of RBC suspension stipulated in the Clinical transfusion technical specifications (2000) by the Chinese Ministry of Health.

The exclusion criteria were as follows: above ASA level III, temperature $>38^{\circ} \mathrm{C}$, a history of coronary heart disease or diabetes, ejection fraction $(\mathrm{EF})<50 \%$, serious liver or kidney dysfunction, long-term use of anticoagulant drugs, severe coagulation disorders, severe chronic obstructive or restrictive pulmonary disease, long-term use of $\beta$-retardants, a history of central nervous system diseases, malnutrition with low weight or obese patients, severe peripheral vascular occlusive disease, intraoperative and postoperative use of erythropoietin (EPO) (6) and receiving hormone therapy. No other factors were considered relevant for the present study.

Anaesthesia methods. The patients were not administered preoperative premedication; however, they were provided with oxygen masks and monitoring electrocardiogram (ECG), heart rate (HR), blood pressure (BP) and pulse oxygen saturation $\left(\mathrm{SpO}_{2}\right)$ after entering the operating room. The peripheral pathway was established by infusing $0.9 \%$ sodium chloride injection for $10 \mathrm{ml} / \mathrm{kg} / \mathrm{h}$ through the left upper limb vein. The left radial artery was punctured for catheterization and connected to an invasive blood pressure monitor and patients were given an oxygen inhalation face mask at $3 \mathrm{l} / \mathrm{min}$. The anaesthetic induction was an intravenous injection of $0.5-1.0 \mu \mathrm{g} / \mathrm{kg}$ sufentanil, $0.1-0.15 \mathrm{mg} / \mathrm{kg}$ midazolam, $0.1 \mathrm{mg} /$ $\mathrm{kg}$ vecuronium bromide and $0.5-1.0 \mathrm{mg} / \mathrm{kg}$ isopropylphenol as well as orotracheal intubation and mechanical ventilation after $5 \mathrm{~min}$. Ventilation parameters were $8-10 \mathrm{ml} / \mathrm{kg}$ tidal volume, 10-12 times/min respiratory rate and sustained respiratory end-tidal carbon dioxide $\left(\mathrm{PETCO}_{2} ; 35-40 \mathrm{mmHg}\right)$. Anesthesia was maintained by continuous intravenous infusion of 4-6 mg/ $\mathrm{kg} / \mathrm{h}$ isopropylphenol and $0.05-0.1 \mathrm{mg} / \mathrm{kg} / \mathrm{h}$ vecuronium bromide and a simultaneous discontinuous inhalation of $1-1.5 \%$ sevoflurane. The non-treatment factors were controlled by the use of air conditioning and electric blankets to keep the nasopharyngeal temperature at $36.5-37.2^{\circ} \mathrm{C}$. The capacity was controlled and $0.9 \%$ sodium chloride injection was infused for $10 \mathrm{ml} / \mathrm{kg} / \mathrm{h}$ before blood transfusion to maintain a stable circulation system. To optimize tissue perfusion adequate colloid or crystalloid fluid was infused in elderly patients. The perioperative 12-lead ECG was monitored to prevent myocardial ischemia and myocardial infarction. Blood loss was quantified in strict accordance with the standard method.

Evaluation method of transfusion. The $\mathrm{Hb}$ within $12 \mathrm{~h}$ of transfusion with a RBC suspension was compared to $\mathrm{Hb}$ prior to blood transfusion to calculate the increment. In accordance with the traditional evaluation method, we estimated that the effective infusion of RBCs was $\sim 5 \mathrm{~g} / 1 \mathrm{Hb}$ increased in every 1 unit transfused RBC suspension or $\sim 10 \mathrm{~g} / \mathrm{l} \mathrm{Hb}$ increased in every 3 units transfused washed RBCs.

For the $\mathrm{Hb}$ and Hct goal-directed RBC transfusion method, a portable i-STAT 1 blood gas analyzer was employed to record peri-operative $\mathrm{Hb}$ and $\mathrm{Hct}$ at varying time points to dynamically monitor the most appropriate time for RBC transfusion, according to the infusion indications of RBC suspension stipulated in the Clinical transfusion technical specifications (2000) by the Chinese Ministry of Health.

As yet there is no evaluation of the effectiveness of blood transfusion in peri-operation of major orthopedic surgery in elderly patients. Older patients with hemorrhage as well as significant transfusion are at risk of postoperative mortality (7). The purpose of blood transfusion is to maintain the balance of oxygen supply and oxygen consumption. The oxygenation index (OI) reflects the balance between body oxygen supply and oxygen consumption, and the change in $\mathrm{Hb}$ and Hct reflects the improved oxygen-carrying capacity prior to and after blood transfusion. OI and $\mathrm{Hb}$ as well as cardiac output $(\mathrm{CO})$ are positively correlated. Cardiac output is reflected by hemodynamic index, heart rate and blood pressure. Therefore, we maintained an intraoperative balance of body oxygen supply and oxygen consumption and produced a standard for evaluating blood transfusion effectiveness through accurate physiological calculation. Scoring was based on indices that are easily monitored, including $\mathrm{Hb}$, Hct, activated partial thromboplastin time (APTT), prothrombin time (PT), OI, blood transfusion complications, wound healing time, length of stay and the number of transfers to the intensive care unit (ICU). As a result, the $\mathrm{Hb}$ and $\mathrm{Hct}$ goal-directed RBC transfusion method was compared to the traditional blood transfusion method in order to establish a standard for evaluation of blood transfusion effectiveness to guide blood transfusion in the peri-operation of major orthopedic surgery in elderly patients.

The evaluation of the ascensional range of $\mathrm{Hb}, \mathrm{Hct}, \mathrm{PT}$, APTT and OI following transfusion of RBC suspension is shown in Table I. The evaluation of the adverse transfusion reactions, as well as complication rate, wound healing time, length of stay and ICU transfer rate is shown in Table II. The transfusion reactions included anaphylactic reactions or anaphylactoid reactions, febrile reactions, electrolytes, acidbase imbalance, citrate poisoning, hypothermia caused by massive transfusion of cold blood, phlebitis after transfusion, transfusion-related lung injury, hemolytic transfusion reaction and transfusion-related infections.

The standard for evaluation of blood transfusion effectiveness was: $<5$, invalid; $>8$, valid and $>10$, highly effective (Tables I and II).

Monitoring indicators. The general data of patients were recorded. Patients were given radial arterial blood gas analysis using a portable blood gas analyzer (i-STAT 1, Abbott Laboratories, IL, USA) after entering the operating room and $\mathrm{Hb}$, Hct and RBC were recorded. The heart rate (HR), blood pressure (BP), temperature (T) and $\mathrm{SpO}_{2}$ were recorded with a S/5 Avance anesthesia machine (Datex Ohmeda, Finland) and a BeneviewT6 patient monitor (Shenzhen Mindray Bio-Medical Electronics Co., Ltd., China). At the same time, 
Table I. Blood transfusion effectiveness score.

\begin{tabular}{lccccc}
\hline Scores & Hb & Hct & PT & APTT & OI (mmHg) \\
\hline 5 & Normal & Normal & Normal & Normal & $>300$ \\
+1 & Increased $1 \mathrm{~g} / \mathrm{dl}$ & Increased 1\% & $-1 \mathrm{sec}$ & $-3 \mathrm{sec}$ & $300-400$ \\
+2 & Increased $2 \mathrm{~g} / \mathrm{dl}$ & Increased 2\% & $-2 \mathrm{sec}$ & $-6 \mathrm{sec}$ & $>400$ \\
\hline
\end{tabular}

$\mathrm{Hb}$, hemoglobin; Hct, hematocrit; PT, prothrombin time; APTT, activated partial thromboplastin time; OI, oxygenation index.

Table II. Blood transfusion effectiveness score.

\begin{tabular}{lcccc}
\hline Scores & Transfusion complications & Wound healing time (days) & Length of stay (days) & ICU transfer rate \\
\hline 5 & None & $<12$ & $<10$ & None \\
-1 & 1 item & $12-15$ & $10-12$ & 1 time \\
-2 & 2 items & $>15$ & $>12$ & $\geq 2$ times \\
\hline
\end{tabular}

ICU, intensive care unit.

the cardiac index (CI), stroke volume index (SVI) and the corresponding systolic blood pressure (SBP), diastolic blood pressure (DBP), mean arterial pressure (MAP) and heart rate $(\mathrm{HR})$ were monitored with a Flotrac sensor and Vigileo monitor (software version 1.07, Edwards Lifesciences, Irvine, CA, USA) to calculate the surrounding vascular resistance $(\mathrm{SVR}=\mathrm{MAP} \times 80 / \mathrm{CO})$ as a basic value (T0). Thereafter, the radial arterial blood gas analysis was performed at $12 \mathrm{~h}$ (T1), $24 \mathrm{~h}$ (T2) and $48 \mathrm{~h}$ (T3) after blood transfusion. At the same time, surgery time (from skin incision to the end of surgery), adverse transfusion reactions, complication rate, wound healing time, length of stay, ICU transfer rate and intraoperative RBC transfer volumes were recorded.

The main monitoring indicators included $\mathrm{Hb}$ and Hct and the secondary monitoring indicators included APTT, PT, $\mathrm{P}(\mathrm{A}-\mathrm{a}) \mathrm{O}_{2}$, OI and Vigileo monitored indicators. Increased $\mathrm{P}(\mathrm{A}-\mathrm{a}) \mathrm{O}_{2}$ caused by pathological factors, including anatomical shunt, ventilation/perfusion imbalance and impeded diffusion of alveolar-capillary barriers was ruled out (8). The computational formula for $\mathrm{P}(\mathrm{A}-\mathrm{a}) \mathrm{O}_{2}$ was as follows: $\mathrm{P}(\mathrm{A}-\mathrm{a}) \mathrm{O}_{2}$ $=[$ atmospheric pressure - water vapor pressure $\mathrm{x}$ fraction of inspired oxygen $\left.\left(\mathrm{FiO}_{2}\right)-\mathrm{PaCO}_{2} / \mathrm{R}\right]-\mathrm{PaO}_{2}$, where the atmospheric pressure was $760 \mathrm{mmHg}$; the water vapor pressure, $47 \mathrm{mmHg}$ and the respiratory quotient (R), 0.8. $\mathrm{PaO}_{2}$ and $\mathrm{PaCO}_{2}$ were measured by arterial blood gas. The formula for OI was as follows: $\mathrm{OI}=\mathrm{PaO}_{2} / \mathrm{FiO}_{2}$.

The outcome indicators that were monitored included adverse transfusion reactions and complication rate, wound healing time, length of stay and ICU transfer rate.

Intraoperative blood loss was monitored and we calculated the observation time in the surgical field and communicated it with the surgeon to evaluate whether there was a significant amount of microvascular bleeding. Standard methods were taken to quantify the blood loss, including suction apparatus, gauze measurement and recycled blood volume. The formula for RBC suspension supplementation was: suspension supple- mentation of RBCs $=[($ predicted Hct - practical Hct $) \times 55 \mathrm{x}$ weight $] / 0.60$.

Statistical analysis. Patients were randomly divided into different groups by the envelope method. Data were analyzed by SPSS 13.0 statistical software (SPSS Inc., Chicago, IL, USA). Measurement data were expressed as mean \pm standard deviation and enumeration data were determined by the univariate $\chi^{2}$ test. Comparison among groups was performed using a t-test and comparison within groups was performed using the variance analysis of repeated measurement data. $\mathrm{P}<0.05$ was considered to indicate a statistically significant difference.

\section{Results}

General data. Intraoperative transfusion of a RBC suspension in 106 patients were all $>2$ units $(400 \mathrm{ml})$ and there were no intraoperative or postoperative transfusion-related allergic reactions or other related complications. There were 3 patients in group 1 that were transferred to the ICU for further treatment, with a transfer rate of $5.6 \%$ and an ICU detention time $>24 \mathrm{~h}$. There were no patients in group 2 that were transferred to the ICU. There was no statistical difference in age, height, weight, body surface area, cardiac function, duration of surgery, intraoperative transfusion volume of RBCs and length of stay between the two groups (P>0.05; Table III).

$\mathrm{Hb}$ and Hct. The comparison of parameters before and after blood transfusion in the two groups (Table II) revealed a significant difference in the $\mathrm{Hb}$ and Hct goal-directed $\mathrm{RBC}$ transfusion method $(\mathrm{P}>0.05)$. There was a statistical difference in RBC and PT before and after blood transfusion in the traditional method of $\mathrm{RBC}$ transfusion $(\mathrm{P}<0.05$; Table IV). Our results indicate that the changes in $\mathrm{Hb}, \mathrm{Hct}, \mathrm{RBC}$, platelet 
Table III. Comparison of general data in patients.

\begin{tabular}{lccc}
\hline Parameters & $\begin{array}{c}\text { Control } \\
\text { group }\end{array}$ & $\begin{array}{c}\text { Experimental } \\
\text { group }\end{array}$ & $\begin{array}{c}\text { P-value } \\
\left(\chi^{2}\right)\end{array}$ \\
\hline Age (years) & $69.2 \pm 5.9$ & $70.1 \pm 5.8$ & 0.974 \\
Gender (n) & & & \\
Male & 24 & 21 & $0.449(0.572)$ \\
Female & 28 & 33 & \\
Height (cm) & $174.2 \pm 7.8$ & $174.3 \pm 4.9$ & 0.941 \\
Weight (kg) & $80.1 \pm 18.1$ & $76.2 \pm 10.1$ & 0.370 \\
Body surface & $2.05 \pm 0.26$ & $2.00 \pm 0.15$ & 0.452 \\
area (m ${ }^{2}$ ) & & & \\
Cardiac function & & & \\
$\begin{array}{l}\text { Grade 1 } \\
\text { Grade 2 }\end{array}$ & 12 & 15 & $0.890(1.270)$ \\
$\begin{array}{l}\text { Duration of } \\
\text { surgery (min) }\end{array}$ & $166.0 \pm 66.7$ & $194.6 \pm 82.4$ & 0.051 \\
$\begin{array}{l}\text { Intraoperative red } \\
\text { blood cells (unit) }\end{array}$ & $2.4 \pm 1.2$ & $2.7 \pm 1.4$ & 0.300 \\
$\begin{array}{l}\text { Length of stay } \\
\text { (days) }\end{array}$ & $20.0 \pm 10.0$ & $22.0 \pm 10.0$ & 0.371 \\
\hline
\end{tabular}

The general conditions of patients in the experimental group were compared to those in the control group ( $\mathrm{P}>0.05$, Chi-square test). Data are presented as the mean \pm standard deviation.

(PLT), PT and APTT before and after blood transfusion are greater in the $\mathrm{Hb}$ and Hct goal-directed RBC transfusion method compared with the traditional method.

$\mathrm{P}(\mathrm{A}-\mathrm{a}) \mathrm{O}_{2}$ difference. There were no significant differences in $\mathrm{P}(\mathrm{A}-\mathrm{a}) \mathrm{O}_{2}$ and OI preoperatively (T0), at $12 \mathrm{~h}$ (T1), $24 \mathrm{~h}$ (T2) or $48 \mathrm{~h}$ (T3) after blood transfusion between the two groups
( $P>0.05$; Table $\mathrm{V}$ ), indicating that there is no difference in $\mathrm{P}(\mathrm{A}-\mathrm{a}) \mathrm{O}_{2}$ change and $\mathrm{OI}$ before and after transfusion between the two groups.

$R B C$ transfusion. Referring to the transfusion indications of $\mathrm{RBC}$ suspension stipulated in the Clinical transfusion technical specifications by the Chinese Ministry of Health, Hb should be 70-100 g/l, which is determined according to the degree of anemia, cardiopulmonary compensatory function, age and whether there is an increased metabolic rate, as well as other factors. In this study, compared to the traditional RBC transfusion method, we noted that in the $\mathrm{Hb}$ and Hct goal-directed RBC transfusion method, $\mathrm{SpO}_{2}$, body temperature and $\mathrm{HR}$ fluctuated when $\mathrm{Hb}<10 \mathrm{~g} / \mathrm{dl}$. Therefore, $\mathrm{Hb}<10 \mathrm{~g} / \mathrm{dl}$ is considered as one of the standards of RBC transfusion in this group (9).

The rate of effectiveness in the traditional and $\mathrm{Hb}$ and Hct goal-directed RBC transfusion methods were 61.5 and $72.2 \%$, respectively. The rate of effectiveness of the $\mathrm{Hb}$ and Hct goal-directed RBC transfusion method is clearly higher than that of the traditional transfusion method.

\section{Discussion}

Our study has demonstrated that compared with the traditional method of RBC transfusion, the $\mathrm{Hb}$ and Hct goal-directed $\mathrm{RBC}$ transfusion method clearly reduces the ratio of invalid RBCs infused, with a blood transfusion inefficiency of 38.5 and $27.8 \%$ respectively. This was due to not excluding ongoing blood loss, blood infiltration outside the blood vessel, fluid hemodilution and RBC loss in the extracorporeal circulation, as well as other factors.

Comparing different parameters before and after blood transfusion in the two groups and at the same time referring to the scoring method of blood transfusion effectiveness, we noted that compared to the group with traditional transfusion, the $\mathrm{RBC}, \mathrm{Hb}$ and Hct in the $\mathrm{Hb}$ and Hct goal-directed

Table IV. Comparison of parameters before and after transfusion.

\begin{tabular}{|c|c|c|c|c|}
\hline Parameters & Group & Before transfusion & After transfusion & P-value \\
\hline \multirow[t]{2}{*}{$\mathrm{RBC}\left(\mathrm{x} 10^{12} / \mathrm{l}\right)$} & $\mathrm{I}$ & $4.0 \pm 0.8$ & $3.8 \pm 0.6$ & 0.033 \\
\hline & II & $4.1 \pm 0.6$ & $3.7 \pm 0.6$ & 0.003 \\
\hline \multirow[t]{2}{*}{ PLT $\left(x 10^{9} / 1\right)$} & I & $209.4 \pm 79.1$ & $213.1 \pm 75.8$ & 0.746 \\
\hline & II & $181.1 \pm 60.1$ & $166.5 \pm 59.0$ & 0.002 \\
\hline \multirow[t]{2}{*}{$\operatorname{Hct}(\%)$} & $\mathrm{I}$ & $38.9 \pm 5.1$ & $38.0 \pm 5.0$ & 0.287 \\
\hline & II & $37.5 \pm 6.3$ & $34.5 \pm 5.6$ & 0.006 \\
\hline \multirow[t]{2}{*}{$\mathrm{Hb}(\mathrm{g} / \mathrm{l})$} & I & $118.7 \pm 19.7$ & $113.4 \pm 17.0$ & 0.161 \\
\hline & II & $126.0 \pm 21.1$ & $119.3 \pm 22.5$ & 0.007 \\
\hline \multirow[t]{2}{*}{ PT (sec) } & $\mathrm{I}$ & $7.1 \pm 2.0$ & $8.0 \pm 2.0$ & 0.032 \\
\hline & II & $8.3 \pm 3.0$ & $7.2 \pm 3.0$ & 0.024 \\
\hline \multirow[t]{2}{*}{ APTT (sec) } & I & $24.0 \pm 6.0$ & $25.0 \pm 5.0$ & 0.057 \\
\hline & II & $23.0 \pm 4.0$ & $25.0 \pm 3.0$ & 0.016 \\
\hline
\end{tabular}

Data are presented as the mean \pm standard deviation. I, control group; II, experimental group; RBC, red blood cell; PLT, platelet; Hct, hematocrit; $\mathrm{Hb}$, hemoglobin; PT, prothrombin time; APTT, activated partial thromboplastin time. 
Table V. Alveolar-arterial oxygen partial pressure difference, oxygenation index and Vigileo monitored indicators at different time points in the two groups.

\begin{tabular}{|c|c|c|c|}
\hline $\begin{array}{l}\text { Monitoring } \\
\text { indicators }\end{array}$ & $\begin{array}{l}\text { Time } \\
\text { point }\end{array}$ & Group I & Group II \\
\hline \multirow{4}{*}{$\begin{array}{l}\mathrm{P}(\mathrm{A}-\mathrm{a}) \mathrm{O}_{2} \\
(\mathrm{mmHg})\end{array}$} & T0 & $21.3 \pm 5.2$ & $20.9 \pm 4.9$ \\
\hline & $\mathrm{T} 1$ & $343.7 \pm 110.2$ & $374.2 \pm 123.1$ \\
\hline & $\mathrm{T} 2$ & $418.5 \pm 95.3$ & $417.4 \pm 137.3$ \\
\hline & $\mathrm{T} 3$ & $208.2 \pm 104.4$ & $181.2 \pm 89.1$ \\
\hline \multirow[t]{4}{*}{ OI } & T0 & $379.4 \pm 32.3$ & $400.0 \pm 23.7$ \\
\hline & $\mathrm{T} 1$ & $322.7 \pm 105.0$ & $290.2 \pm 123.4$ \\
\hline & $\mathrm{T} 2$ & $239.2 \pm 95.1$ & $229.6 \pm 166.8$ \\
\hline & $\mathrm{T} 3$ & $227.2 \pm 98.2$ & $243.9 \pm 119.3$ \\
\hline \multirow{4}{*}{$\begin{array}{l}\text { MAP } \\
(\mathrm{mmHg})\end{array}$} & T0 & $94 \pm 17$ & $97 \pm 15$ \\
\hline & $\mathrm{T} 1$ & $81 \pm 19$ & $80 \pm 13$ \\
\hline & $\mathrm{T} 2$ & $76 \pm 14$ & $68 \pm 13$ \\
\hline & $\mathrm{T} 3$ & $81 \pm 10$ & $80 \pm 7$ \\
\hline \multirow{4}{*}{$\begin{array}{l}\text { HR } \\
(\mathrm{bpm})\end{array}$} & T0 & $75 \pm 13$ & $67 \pm 21$ \\
\hline & $\mathrm{T} 1$ & $74 \pm 15$ & $69 \pm 13$ \\
\hline & $\mathrm{T} 2$ & $78 \pm 14$ & $67 \pm 13^{a}$ \\
\hline & $\mathrm{T} 3$ & $95 \pm 15$ & $109 \pm 15^{\mathrm{a}}$ \\
\hline \multirow{4}{*}{$\begin{array}{l}\text { CI } \\
\left(1 / \mathrm{min} / \mathrm{m}^{2}\right)\end{array}$} & T0 & $3.1 \pm 0.7$ & $3.6 \pm 0.8$ \\
\hline & $\mathrm{T} 1$ & $2.6 \pm 0.7$ & $2.8 \pm 0.6$ \\
\hline & $\mathrm{T} 2$ & $2.8 \pm 0.6$ & $2.5 \pm 0.4^{\mathrm{a}}$ \\
\hline & $\mathrm{T} 3$ & $3.5 \pm 0.8$ & $3.3 \pm 0.7$ \\
\hline \multirow{4}{*}{$\begin{array}{l}\text { SVI } \\
\left(\mathrm{ml} / \text { beat } / \mathrm{m}^{2}\right)\end{array}$} & T0 & $41 \pm 10$ & $46 \pm 13$ \\
\hline & $\mathrm{T} 1$ & $37 \pm 10$ & $41 \pm 7$ \\
\hline & $\mathrm{T} 2$ & $37 \pm 7$ & $40 \pm 8$ \\
\hline & $\mathrm{T} 3$ & $38 \pm 6$ & $33 \pm 6^{\mathrm{a}}$ \\
\hline \multirow{4}{*}{$\begin{array}{l}\text { SVR } \\
\left(\text { dynes-sec/cm }{ }^{5}\right)\end{array}$} & T0 & $1375 \pm 258$ & $1243 \pm 318$ \\
\hline & $\mathrm{T} 1$ & $2525 \pm 535$ & $2362 \pm 359$ \\
\hline & $\mathrm{T} 2$ & $1247 \pm 264$ & $1258 \pm 340$ \\
\hline & $\mathrm{T} 3$ & $1058 \pm 288$ & $1110 \pm 258$ \\
\hline
\end{tabular}

${ }^{\mathrm{a}} \mathrm{P}<0.05$ vs group 1 . Data are presented as the mean \pm standard deviation. $\mathrm{P}(\mathrm{A}-\mathrm{a}) \mathrm{O}_{2}$, alveolar-arterial oxygen partial pressure; OI, oxygenation index; MAP, mean arterial pressure; HR, heart rate; CI, cardiac index; SVI, stroke volume index; SVR, surrounding vascular resistance.

RBC transfusion patients increased, APTT and PT decreased, wound healing time and hospitalization days shortened and ICU transfer rate reduced $(\mathrm{P}<0.05)$. There was no statistical difference in $\mathrm{P}(\mathrm{A}-\mathrm{a}) \mathrm{O}_{2}$ changes or OI between the two groups in the peri-operative period $(\mathrm{P}>0.05)$. The reason for this may be related to normal or compensatory cardiopulmonary function in orthopedic elderly patients. At the same time, intraoperative RBC suspension volumes in 106 patients were all $>2$ units $(400 \mathrm{ml})$ and there were no intraoperative and postoperative allergic reactions or other complications related to blood transfusion. The wound healing time and number of hospitalization days in group 1 were significantly higher than those in group 2. Three patients in group 1 were transferred into the ICU for further treatment, with a transfer rate of $5.6 \%$ and ICU detention time was $>24 \mathrm{~h}$. No patients were transferred into the ICU from group 2.

This study aimed to establish a clinical scoring method to correctly evaluate the effectiveness of blood transfusion to achieve scientific, reasonable and effective blood transfusion. A number of studies have evaluated the effectiveness of RBC transfusion $(10,11)$ with regard to whether $\mathrm{Hb}$ achieved the expected value after blood transfusion; however, there has been no evaluation of whether the clinical symptoms of the patients improved or monitoring of complications following blood transfusion (12). Low $\mathrm{Hb}$ in surgery patients may increase the incidence rate of postoperative complications $(13,14)$, including the extension of postoperative recovery time $(15,16)$ and an increase in postoperative infection susceptibility $(17,18)$. Analysis of patients with postoperative $\mathrm{Hb}<8 \mathrm{~g} / \mathrm{dl}$ revealed that the mortality rate increased for postoperative $\mathrm{Hb}<7 \mathrm{~g} /$ dl (19). When $\mathrm{Hb}$ was $<6 \mathrm{~g} / \mathrm{dl}$, memory changes appeared (20) and when $\mathrm{Hb}$ was $<5 \mathrm{~g} / \mathrm{dl}$, the mortality significantly increased $(21,22)$. In this study, the blood transfusion strategy using $\mathrm{Hb}$ and Hct goal-direction may not only effectively save $10.7 \%$ blood, but also significantly reduce the wound healing time, number of hospitalization days and ICU transfer rate to significantly improve patient outcome and prognosis.

The limitations of this study are that it was a randomized control study in a single center with a small sample size and the objects of the study were older patients undergoing orthopedic surgery. Therefore, further investigation is required to determine whether this evaluation method of blood transfusion effectiveness is also applicable to other patients with different types or ages.

The scoring method of blood transfusion effectiveness was established through comparing the $\mathrm{Hb}$ and Hct goal-directed $\mathrm{RBC}$ transfusion method to the traditional RBC transfusion method. Our findings indicated that the $\mathrm{Hb}$ and $\mathrm{Hct}$ goal-directed RBC transfusion method improves the blood transfusion effectiveness in the peri-operative period of major orthopedic surgery in elderly patients. At the same time we identified that $\mathrm{Hb}<10 \mathrm{~g} / \mathrm{dl}$, as one of the blood transfusion standards in orthopedic elderly patients, improves the blood transfusion effectiveness in the peri-operative period of major orthopedic surgery in elderly patients. The ineffectiveness of $\mathrm{RBC}$ transfusion is mainly related to postoperative blood loss, the isoimmunization of multiple transfusions and accelerated destruction, as well as other factors. Therefore, minimizing the number of blood transfusions, as well as controlling infection and fever may improve the effectiveness of RBC transfusion treatment.

\section{Acknowledgements}

This study was supported by the construction fund of key discipline (Anesthesiology) of Xinjiang Uygur Autonomous Region.

\section{References}

1. Leung JM and Dzankic S: Relative importance of preoperative health status versus intraoperative factors in predicting postoperative adverse outcomes in geriatric surgical patients. Am Geriatr Soc 49: 1080-1085, 2001. 
2. Dunne JR, Malone D, Tracy JK, Gannon C and Napolitano LM: Perioperative anemia: an independent risk factor for infection, mortality, and resource utilization in surgey. J Surg Res 102: 237-244, 2002

3. Gruson KI, Aharonoff GB, Egol KA, Zuckerman JD and Koval KJ: The relationship between admission hemoglobin level and outcome after hip fracture. J Orthop Trauma 16: 39-44, 2002.

4. Hardy JF, de Moerloose P and Samama CM: Massive transfusion and coagulopathy: pathophysiology and implications for clinical management. Can J Anaesth 53: S40-S58, 2006.

5. Harvey MP, Greenfield TP, Sugrue ME and Rosenfeld D: Massive blood transfusion in a tertiary referral hospital. Clinical outcomes and haemostatic complications. Med J Aust 163: 356-359, 1995.

6. Bohlius J, Schmidlin K, Brillant C, et al: Recombinant human erythropoiesis-stimulating agents and mortality in patients with cancer: a meta-analysis of randomised trials. Lancet 373 . 15321542,2009

7. Seghatchian J and Samama MM: Massive transfusion: an overview of the main characteristics and potential risks associated with substances used for correction of a coagulopathy. Transfus Apher Sci 47: 235-243, 2012.

8. Ronnie AR and Stephen MK: Assessment and management of the geriatric patient. Crit Care Med 32: S92-S105, 2004.

9. Goodnough LT, Maniatis A and Earnshaw P: Management of preoperative anaemia in patients undergoing elective surgery. ISBT Sci Ser 5: 120-124, 2010

10. Johansson PI, Ostrowski SR and Secher NH: Management of major blood loss: an update. Acta Anaesthesiol Scand 54: 1039-1049, 2010.

11. Lee A, Kerridge RK, Chui PT, Chiu CH and Gin T: Perioperative systems as a quality model of perioperative medicine and surgical care. Health Policy 102: 214-222, 2011.

12. Heddle NM, Arnold DM, Boye D, Webert KE, Resz I and Dumont LJ: Comparing the efficacy and safety of apheresis and whole blood-derived platelet transfusions: systematic review. Transfusion 48: 1447-1458, 2008.
13. Kuriyan M and Carson JL: Anemia and clinical outcomes. Anesthesiol Clin North Am 23: 315-325, vii, 2005.

14. Greenblatt DY, Rajamanickam V and Mell MW: Predictors of surgical site infection after open lower extremity revascularization. J Vasc Surg 54: 433-439, 2011.

15. Carson JL, Terrin ML and Jay M: Anemia and postoperative rehabilitation. Can J Anaesth 50: S60-S64, 2003.

16. Giles KA, Hamdan AD, Pomposelli FB, Wyers MC, Siracuse JJ and Schermerhorn ML: Body mass index: surgical site infections and mortality after lower extremity bypass from the National Surgical Quality Improvement Program 2005-2007. Ann Vasc Surg 24: 48-56, 2010.

17. O'Keeffe SD, Davenport DL, Minion DJ, Sorial EE, Endean ED and Xenos ES: Blood transfusion is associated with increased morbidity and mortality after lower extremity revascularization. J Vasc Surg 51: 616-621, 2010.

18. Lindholm PF, Annen K and Ramsey G: Approaches to minimize infection risk in blood banking and transfusion practice. Infect Disord Drug Targets: Aug 10, 2010 (Epub ahead of print).

19. Cuenca J, Garcia-Erce JA, Martinez F, Cardona R, Pérez-Serrano L and Muñoz M: Preoperative haematinics and transfusion protocol reduce the need for transfusion after total knee replacement. Int J Surg 5: 89-94, 2007.

20. Weiskopf RB, Kramer JH, Viele M, et al: Acute severe isovolemic anemia impairs cognitive function and memory in humans. Anesthesiology 92: 1646-1652, 2000.

21. Carson JL, Noveck H, Berlin JA and Gould SA: Mortality and morbidity in patients with very low postoperative $\mathrm{Hb}$ levels who decline blood transfusion. Transfusion 42: 812-818, 2002.

22. Ferraris VA, Davenport DL, Saha SP, Austin PC and Zwischenberger JB: Surgical outcomes and transfusion of minimal amounts of blood in the operating room. Arch Surg 147: 49-55, 2012. 